\title{
DYNAMIC RESPONSE OF TENSION LEG PLATFORM WITH TUNED MASS DAMPERS
}

Srinivasan Chandrasekaran ${ }^{1 *}$, Deepak Kumar ${ }^{2}$ and Ranjani Ramanathan ${ }^{3}$

${ }^{1}$ Department of Ocean Engineering, Indian Institute of Technology Madras, Chennai 600036, INDIA,

*Email: drsekaran@iitm.ac.in; Fax: +91-044-22574802.

${ }^{2}$ Department of Ocean Engineering, Indian Institute of Technology Madras, Chennai 600036, INDIA,

Email: deepakkumar@iitm.ac.in

${ }^{3}$ Research Scholar, Department of Ocean Engineering, Indian Institute of Technology Madras, Chennai 600036, INDIA, Email: renjiram2k@gmail.com

\begin{abstract}
:
Tension Leg Platform (TLP) is a taut-moored compliant offshore platform that deploys tethers under high initial pretension to counteract the excess buoyancy. TLPs show large amplitude responses under the encountered lateral forces, which challenges the serviceability of the platform in critical sea states. One of the passive control device i.e. Tuned Mass Damper (TMD) is attempted in the present study to control large amplitude motion of TLPs. In the present study, response control of TLP using single and multiple TMDs is compared. Optimized parameters of multiple tuned mass dampers (MTMD) are obtained using $\mathrm{H}_{2}$ optimization algorithm for the maximum control of the motion of the platform. Based on the studies conducted, it is seen that MTMD systems show better response control in comparison to the single TMD. Higher robustness of the MTMD system is also examined to highlight the use of MTMD over a wide range of excitation frequencies in extreme sea states.
\end{abstract}

Keywords:Tension leg platform, tuned mass damper, multi tuned mass damper, mass ratio

\section{Introduction}

Compliant offshore structures, located in hostile environment, experience high dynamic forces from wind, waves, current and earthquake; this has been a primary concern for engineers and researchers. It is necessary that these structures should not only withstand the encountered forces in the normal operating conditions but also remain safe even during the extreme conditions.Springing and ringing type responses of TLPs under extreme waves pose serious threat to the survivability (Chandrasekaranet al.,2010 c; 2011; Chandrasekaranand Yuvraj,2013). TLPs are also posed to Mathieu-type instability, which needs a special attention that governs the tether failure (Chandrasekaranet al.,2006; Chandrasekaranand Bhattacharyya, 2012). A considerable amount of research is reported on the design and effectiveness of TMD on the structural control. TMD is a passive control device with a mass, spring and a viscous damper system attached to the primary vibrating structure to control the vibration of the primary structure.Fahimet al(2008) studied the effectiveness of TMD for reducing the seismic excitation on structures while Kareem(1983) analyzed the reduction of wind-induced response in the tall buildings with a TMD. Nam et al. (1997)suggested the optimal design parameters of damper for structures under seismic excitations.To improve safety and operability of compliant structures, a few studies are reported in the recent past. Alexandroset al.(2009) recommended a simulation based design for parameter optimization of response mitigation of tension leg platforms (TLP); their focus is on the control of heave and pitch motion of the platform using TMD. Studies show a significant reduction in the response of offshore articulated towers by deploying TMDs(Chandrasekaranet al.,2010a, b). Experimental investigations carried out on the scaled model of multi-leg articulated towers showed effective deployment of TMD to reduce the dynamic amplification factor of the response under regular waves (Chandrsekaranet al.,2010b; Lino, 2012).

Tuned mass dampers are widely used as passive control devicesdue to many factors namely: i) their effectiveness in controlling the vibration of the primary structure; ii) easy design procedure; and iii) its robustness. However, in case of multi TMD system, optimization technique is required to determine the control parameters. From the studies reported in the literature, it is seen that the optimization technique to derive stiffness and damping parameters are more effective in the response control of structures under random loading (Zuo and Nayfeh. 2005; Zuo, 2009; Kareem and Kline, 1995). Researchers have largely shown that $\mathrm{H}_{\infty}$ and $\mathrm{H}_{2}$ optimization techniques are used for obtaining the optimal parameters of multi tuned mass damper system 
(Toshihiko et al., 2002). Present study used two TMDs, placed in series and compares the effectiveness of the response control with that of a single TMD. The optimum parameters are derived using $\mathrm{H}_{2}$ algorithm.

\section{Single Tuned Mass Damper}

A single TMD is a spring mass system, which is attached to the primary system to control its response. A schematic diagram of a TMD, attached to a single degree-of-freedom model is shown in the Fig. 1. Eventhough the concept and design of TMD is simple, its parameters like mass, stiffness and damping ratio need to be optimized for the effective control of response.Equation of motion of the single degree-of-freedom system, deployed with the TMD is given by:

$$
\left.\begin{array}{cc}
M_{s} & 0 \\
0 & m_{1}
\end{array}\right]\left[\begin{array}{l}
\ddot{x}_{s} \\
\ddot{x}_{1}
\end{array}\right]+\left[\begin{array}{cc}
K_{s}+k_{1} & -k_{1} \\
-k_{1} & k_{1}
\end{array}\right]\left[\begin{array}{l}
x_{s} \\
x_{1}
\end{array}\right]=\left[\begin{array}{c}
P \sin \omega t \\
0
\end{array}\right]
$$

Fig.1: Single TMD system

where, $M_{S}$ is the primary and $m_{l}$ is the secondary mass of the structure, $K_{S}, K_{l}$ are the stiffness of the primary structure and TMD, $x_{S}, x_{l}$ are the responses of the primary structure and TMD, respectively. Joshi and Jangid (1997) suggested the optimal parameters for the design of TMD as given below:

$$
\begin{gathered}
\text { Mass ratio } \mu=m_{1} / M_{s} \\
\text { Frequency ratio } f=\frac{1}{1+\mu} \\
\text { Damping ratio } \zeta_{\text {opt }}=\sqrt{\frac{\mu(1+0.75 \mu)}{4(1+\mu)(1+0.5 \mu)}}=\frac{\omega_{d}}{\omega_{s}}
\end{gathered}
$$

where, $\omega_{s}, \omega_{d}$ are the natural frequency of the structure and TMD. The natural frequencies of the TMD and the main structure are nearly equal so as to ensure transfer of the maximum energy during vibration is transferred and subsequently dissipated by the TMD. For the increase in the mass ratio, the damping ratio increases and hence more damping is incorporated into the system for better response control.Therefore, mass ratio is one of the important parameter in the design of TMD. A TMD with lesser mass ratio has larger movement relative to that of the primary structure. This problem could be solved by connecting another mass in series to the secondary mass and thus converting into a multi TMD.

\section{Multiple Tuned Mass Damper System}

Fig. 2 shows the configuration of multiple TMD in series. In order to get the minimum response of the primary structure, the stiffness $\left(k_{1} \& k_{2}\right)$ and the damping factors $\left(c_{1} \& c_{2}\right)$ need to be optimized; this is achieved uisng $\mathrm{H}_{2}$ optimization along with the Lyapunov technique to obtain the response. The mass ratio is now considered as the sum of the masses, connected inseries to the primary mass and is given by:

$$
\mu=\frac{m_{1}+m_{2}}{M_{s}}
$$

The equation of motion for the series configuration is given by:

$$
\left[\begin{array}{ccc}
M_{s} & 0 & 0 \\
0 & m_{1} & 0 \\
0 & 0 & m_{2}
\end{array}\right]\left[\begin{array}{l}
\ddot{x}_{s} \\
\ddot{x}_{1} \\
\ddot{x}_{2}
\end{array}\right]+\left[\begin{array}{ccc}
C_{s}+C_{1} & -c_{1} & 0 \\
-c_{1} & c_{1}+c_{2} & -c_{2} \\
0 & -c_{2} & c_{2}
\end{array}\right]\left[\begin{array}{c}
\dot{x}_{s} \\
\dot{x}_{1} \\
\dot{x}_{2}
\end{array}\right]+\left[\begin{array}{ccc}
K_{s}+k_{1} & -k_{1} & 0 \\
-k_{1} & k_{1}+k_{2} & -c_{2} \\
0 & -k_{2} & k_{2}
\end{array}\right]\left[\begin{array}{c}
x_{s} \\
x_{1} \\
x_{2}
\end{array}\right]=\left[\begin{array}{c}
P \\
0 \\
0
\end{array}\right](6)
$$

The above equation is required to be converted into state space to utilize $\mathrm{H}_{2}$ optimization. 


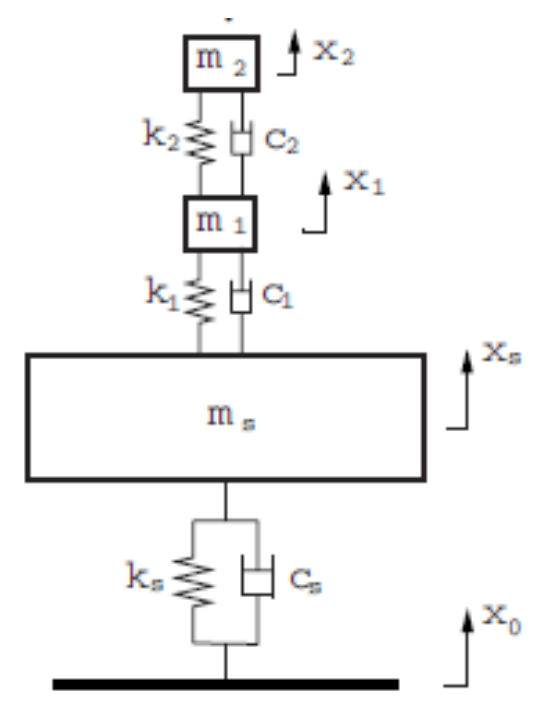

Fig. 2 Multi tuned mass damper in series

\section{State Space Representation}

Second order differential equations of motion, transformed into state space are given by:

where,

$$
\begin{gathered}
z=\left[C_{1}\right] x+\left[D_{11}\right] w+\left[D_{12}\right] u(8) \\
y=\left[C_{2}\right] x+\left[D_{21}\right]
\end{gathered}
$$

$$
\dot{x}=[A] x+\left[B_{1}\right] w+\left[B_{2}\right] u(7)
$$

$y=$ Vector of relative displacements and velocities between the masses

$=\left[x_{1}-x_{s}, \dot{x}_{1}-\dot{x}_{s}, x_{2}-x_{1}, \dot{x}_{2}-\dot{x}_{1}, \ldots x_{N}-x_{N-1}, \dot{x}_{N}-\dot{x}_{N-1}\right]$

$z=$ Performance output (vibration amplitude of the primary mass) $=x_{s}$

$w=$ Disturbance input

$u=$ Force on the mass by stiffness and damping given by,

$$
u_{1}=k_{1}\left(x_{1}-x_{s}\right)+c_{1}\left(\dot{x}_{1}-\dot{x}_{s}\right)
$$

In general,

$$
u_{i+1}=k_{i+1}\left(x_{i+1}-x_{i}\right)+c_{i+1}\left(\dot{x}_{i+1}-\dot{x}_{i}\right)
$$

In the case of theseries arrangement, $u$ can be written in matrix form as

$$
u=\left[\begin{array}{l}
u_{1} \\
u_{2}
\end{array}\right]=\left[\begin{array}{cccc}
k_{1} & c_{1} & 0 & 0 \\
0 & 0 & k_{2} & c_{2}
\end{array}\right][y]=\left[F_{d}\right] y
$$

$u$ is called as the control input since the stiffness and damping parameters are user defined such that the performance output must be as minimized; for a minimum value of the performance output, $(\mathrm{z}), F_{d}$ is optimized.

\section{ParametricOptimization using $\mathrm{H}_{2}$ Algorithm}

In this optimization algorithm, matrices in equation (7-9), which are in the state space representation of the series configurationare used as follows:

$$
\begin{aligned}
& A_{c}=A+B_{2} F_{d} C_{2} \\
& B_{c}=B_{1}+B_{2} F_{d} D_{21} \\
& C_{c}=C_{1}+D_{12} F_{d} C_{2} \\
& D_{c}=D_{11}+D_{12} F_{d} D_{21}
\end{aligned}
$$

The main objective is to optimize the parameters of the matrix $F_{d}$, which comprise of the stiffness and damping factors of masses attached in series; objective is to obtain the minimum response of the primary mass. Using $\mathrm{H}_{2}$ algorithm, we get: 


$$
H_{2}^{2}=\operatorname{trace}\left(B_{c}^{\prime} K B_{c}\right)
$$

Matrix $K$, used above is a symmetric matrix and it is obtained from Lyapunov equation, which is given by: $A_{c}^{\prime} K+K A_{c}+C_{c}^{\prime} C_{c}=0$

After substituting for $A_{C}$ and $C_{c}$, Eq.(18) can be written as:

$$
\left[A+B_{2}\left(F_{d}\right) C_{2}\right]^{\prime} K+K\left[A+B_{2}\left(F_{d}\right) C_{2}\right]+\left[C_{1}+D_{12}\left(F_{d}\right) C_{2}\right]^{\prime}\left[C_{1}+D_{12}\left(F_{d}\right) C_{2}\right]=0(19)
$$

Matrix $\mathrm{K}$ can be obtained by solving the Lyapunov equation (Eq.18) for a initial value of $F_{d} . H_{2}^{2}$ (eq.17) can be then be obtained for any initial value of $F_{d}$. The above two equations can be used along with the minimization algorithm (minimizing $H_{2}^{2}$ ) to obtain the optimum value of $F_{d}$. This shall yield the optimum parameters of the tuned mass dampers for the minimum response of the primary system, to which it is attached.

\section{TLP with Tuned Mass Damper}

The influence of single TMD and multi tuned mass dampers, comprising two TMDs in series on the TLP is examined. The details of the platform considered for the analysis are given in Table 1 and shown in Fig. 3.

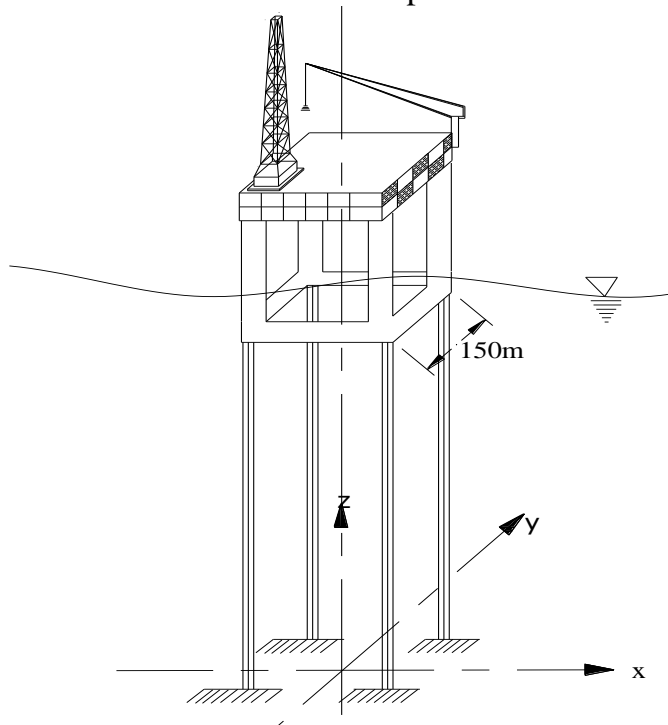

(a)

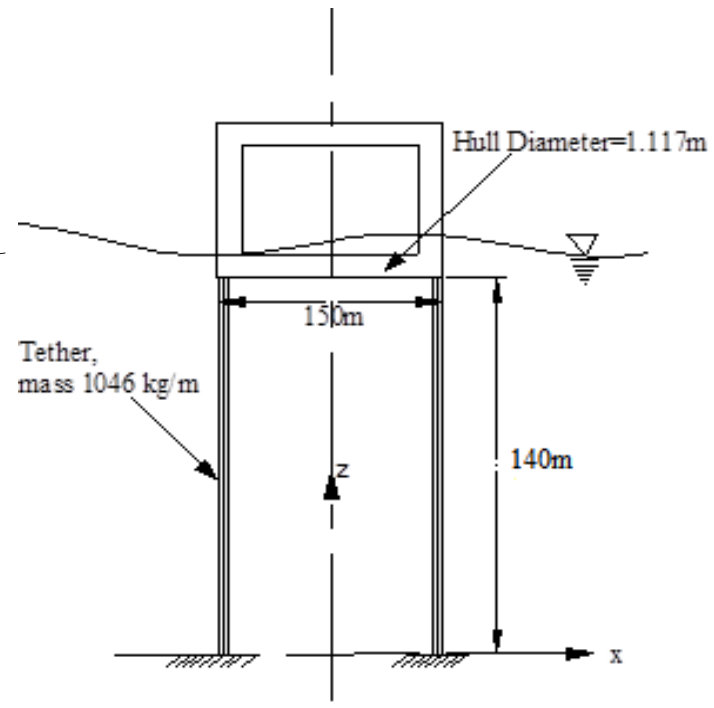

(b)

Fig.3 Tension Leg Platform: (a) 3D view; (b) 2D view

Random sea loading, used in the analysis is given by the Pierson Moskowitz spectrum, as given below:

$$
S(\omega)=5 \pi^{4} \frac{H_{s}{ }^{2}}{T_{p}{ }^{4}} \omega^{-5} \exp \left(-20 \times \omega^{-4} \times\left(\frac{\pi}{T_{p}}\right)^{4}\right)
$$

where, $H_{s}$ is the significant wave height(m), $T_{p}$ is the peak time period(s) and $\omega$ is the frequency in $(\mathrm{rad} / \mathrm{sec})$. The platform is examined only for the surge motion, in the present study. Lateral forces per unit length of the member are calculated using Morison equation and isgiven by:

$$
F=\frac{1}{2} \rho C_{d} A_{p}|U| U+\rho C_{m} V_{o} \dot{U}
$$

where, $A_{p}$ is the projected frontal area, $V_{o}$ is the displaced volume of the structure, $\rho$ is the density of water. The horizontal velocity and acceleration of the water particle are given by:

$$
\begin{aligned}
& U=\frac{\pi H}{T} \frac{\cosh k(z+h)}{\cosh k h} \cos (k x-\omega t) \\
& \dot{U}=\frac{2 \pi^{2} H}{T^{2}} \frac{\cosh k(z+h)}{\sinh k h} \sin (k x-\omega t)
\end{aligned}
$$

where, $H$ is the wave height, $T$ is the time period, $z$ is water depth where force is to be determined, $h$ is total water depth, $k$ is wave number and $\omega$ frequency of wave.The TLP hull is discretized into number of 
elements and the force, in each element is computed in the surge direction. Fig. 4 shows the force spectrum for TLP in the surge direction.

Table1:Structural details of the Tension Leg Platform

\begin{tabular}{|l|l|}
\hline Length & $150 \mathrm{~m}$ \\
\hline Breath & $150 \mathrm{~m}$ \\
\hline External diameter of Hull $(D)$ & $1.1176 \mathrm{~m}$ \\
\hline Total mass of TLP & $30375 \mathrm{MT}$ \\
\hline Water depth & $140 \mathrm{~m}$ \\
\hline Natural time period(surge) & $30 \mathrm{sec}$ \\
\hline
\end{tabular}

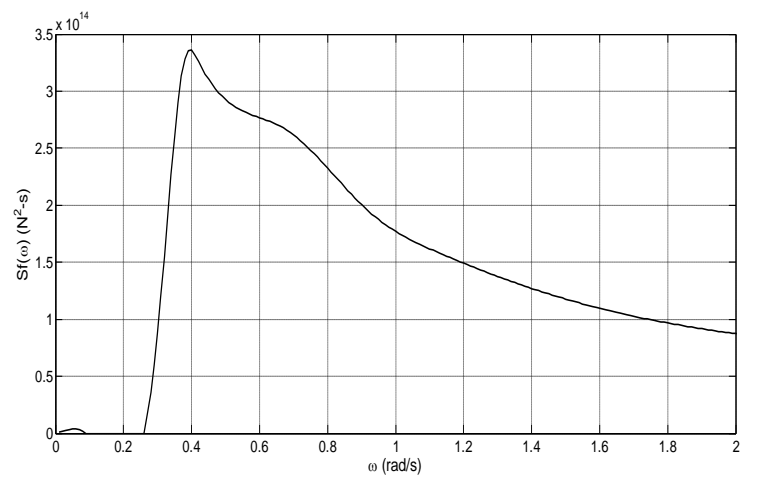

Fig. 4: Force spectrum for TLP in surge direction using P- M spectrum

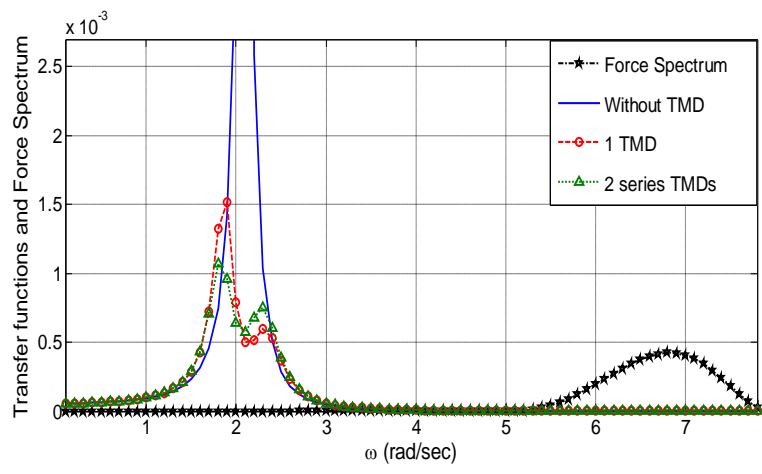

Fig.5: Transfer function amplitudes of primary mass $(6 \mathrm{~m}, 10 \mathrm{~s})$

The load cases considered for the study are for a combination of significant wave height and time period $\left(\mathrm{H}_{\mathrm{s}}, \mathrm{T}_{\mathrm{z}}\right)$ of $(6 \mathrm{~m}, 10 \mathrm{~s})$ and $(12 \mathrm{~m}, 15 \mathrm{~s})$. An additional case of $12 \mathrm{~m}$ wave height and wind speed of $90 \mathrm{~km} / \mathrm{hr}$ is also considered for the analysis. The load combinations are chosen to insight the effect of frequency contents of loading on the response behavior and control algorithm. The displacement response spectrum for TLP is obtained for all these load cases.A single TMD with a mass ratio of 5\% is considered.Parameters of the multi TMD system, in series configuration are obtained using $\mathrm{H}_{2}$ optimization. The optimized parameters are given in Table. 2.

Table 2:Optimized parameters of multi-tuned mass dampers (in series)

\begin{tabular}{|c|c|}
\hline Parameters & Optimized value \\
\hline $\mathrm{m} 1$ & $750 \mathrm{MT}$ \\
\hline $\mathrm{m} 2$ & $750 \mathrm{MT}$ \\
\hline $\mathrm{k} 1$ & $74750 \mathrm{~N} / \mathrm{m}$ \\
\hline $\mathrm{k} 2$ & $45808 \mathrm{~N} / \mathrm{m}$ \\
\hline $\mathrm{C} 1$ & $0 \mathrm{~N}-\mathrm{s} / \mathrm{m}$ \\
\hline $\mathrm{C} 2$ & $263770 \mathrm{~N}-\mathrm{s} / \mathrm{m}$ \\
\hline
\end{tabular}

Force spectrum and the transfer functions of the primary mass are plotted together in order to investigate their interaction.All the force spectra in the following plots have been de-magnified in order to observe their interaction with transfer functions, because the spectral values of the forcing function are very high when compared to that of the transfer functions of the platform.For the load case of $(6 \mathrm{~m}, 10 \mathrm{~s})$, Figs. 5 and 6 show the transfer function of the primary mass and PSDF of the response of the primary mass for all the three configurations namely: i) without TMD; ii) with single TMD; and iii) with two TMDs in series.

It is seen from the Fig. 5 that the force spectrum is a way far from transfer function amplitudes of the primary mass for all three configurations, making the contribution of the force spectra to response of the system negligible. As the response of the system in frequency domain is the product of its transfer function amplitudes and forcing function, the response of the primary mass is very small due to the lower values of the force spectrum interacting with the transfer function. In this case, TMDs do not respond to the loading due to the lower energy of excitation. This can be seen from the Fig. 6, which shows that there is no effect of the presence of TMD on the response of the primary mass. Therefore, RMS of the displacement of the primary mass for the 
three configurations is computed as $0.4 \mathrm{~m}$. For the load case of $(6 \mathrm{~m}, 10 \mathrm{~s})$, Figs. 5 and 6 show the transfer function of the primary mass and PSDF of the response of the primary mass for all the three configurations namely: i) without TMD; ii) with single TMD; and iii) with two TMDs in series. For the load case of (12m, 15s), Figs. 7 and 8 show the transfer function of the primary mass and PSDF of the response of the primary mass for all the three configurations namely: i) without TMD; ii) with single TMD; and iii) with two TMDs in series.

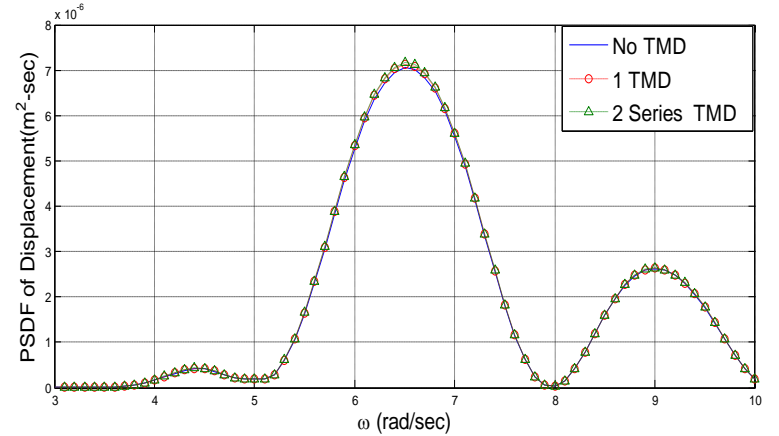

Fig.6 PSDF of the response of primary mass $(6 \mathrm{~m}, 10 \mathrm{~s})$

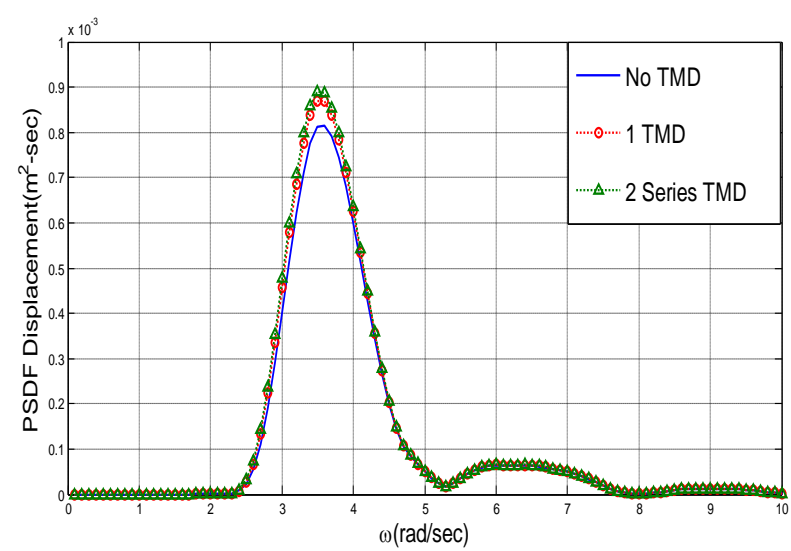

Fig.8: PSDF of the response of primary mass $(12 \mathrm{~m}, 15 \mathrm{~s})$

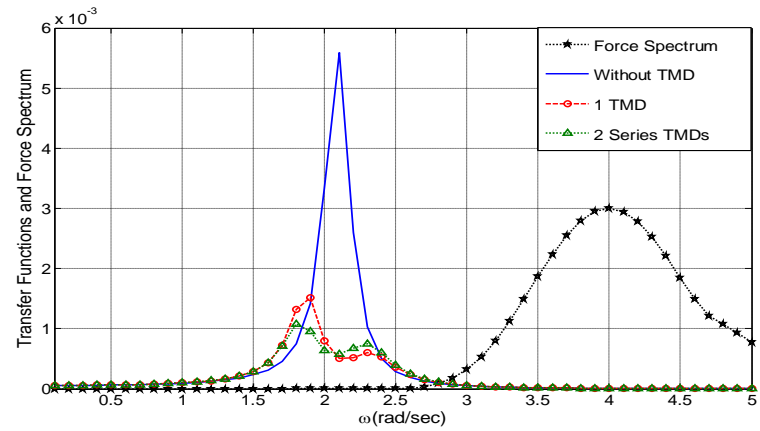

Fig.7 Transfer function amplitude of primary mass $(12 \mathrm{~m}, 15 \mathrm{~s})$

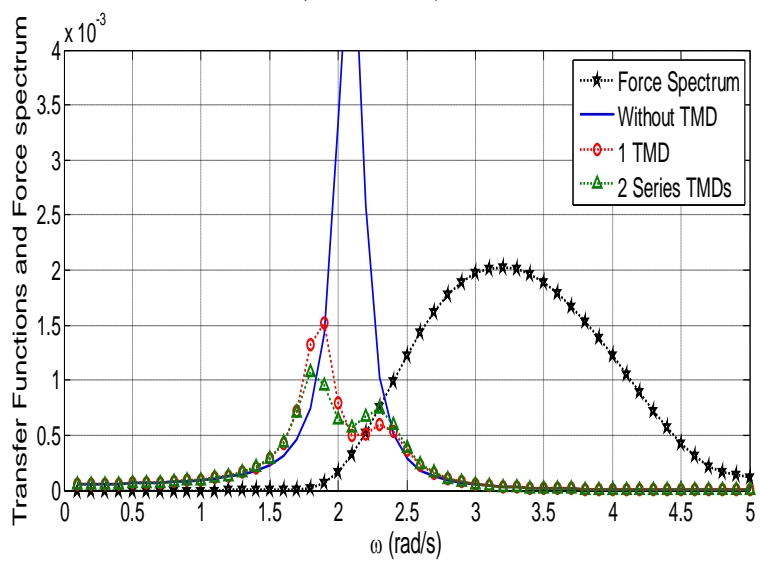

Fig. 9: Transfer function amplitudes of primary mass $\left(\mathrm{H}_{\mathrm{s}}=12 \mathrm{~m}\right.$; wind speed $\left.90 \mathrm{~km} / \mathrm{hr}\right)$

When compared to the previous loading case, the force spectrum in the present case seems to have more energy near the structural frequency due to increase in the significant wave height and peak time period. This results in the shift of the spectrum towards the natural time period $(3 \mathrm{~s})$ of the structure. For the range of frequency where the force spectrum is significantly contributing, it is seen from the Fig 7that the values of the transfer function amplitude, with series TMDs and single TMD are marginally higher than those without TMD. Hence response of the primary mass is increasing when it is attached with a single or teo TMDs in series. It can also be seen that the level of interaction of the response spectrum with both the TMD configurations are almost same. The response of primary structure with and without TMD can be seen in Fig. 8. It clearly shows that the displacement of the primary mass, with TMDs (both single and multi TMDs) is higher than that of the without TMD. This implies the fact that the control of the response by deploying TMDs is not significant for this load case. However, it is to be noted that this load case is a highly unexpected load case for sea states where TLPs are deployed.RMS of the displacement of the primary mass shows an increase in $4 \%$ for the case when the TMDs are attached. For the loading case of significant wave height of $12 \mathrm{~m}$ and wind speed of $90 \mathrm{~km} / \mathrm{hr}$, following equation, which corresponds to the extreme sea stateis used:

$$
\begin{aligned}
& S(\omega)=\frac{5}{16 f_{0}} \frac{H_{s}^{2}}{\left(\omega / f_{0}\right)^{5}} \exp \left(-\frac{5}{4} \times\left(\frac{\omega}{f_{0}}\right)^{-4}\right) \\
& f_{0}=\frac{2 \pi}{\left(1.94 \times 10^{0.5}\right)+\left(2.5 \times 10^{-7} \times u^{4}\right)}
\end{aligned}
$$

where, $u=$ Wind speed in $\mathrm{km} / \mathrm{h}$ 
Figs. 9 and 10 show the transfer function of the primary mass and PSDF of the response of the primary mass for all the three configurations namely: i) without TMD; ii) with single TMD; and iii) with two TMDs in series.

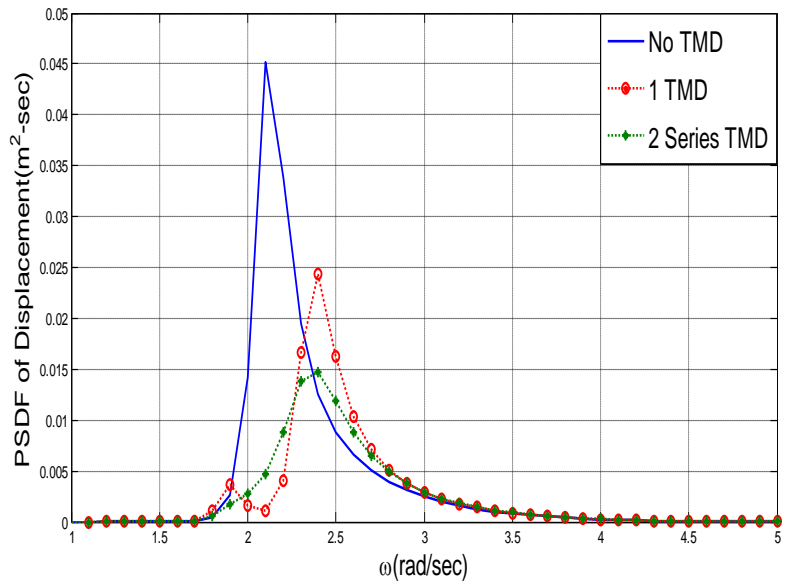

Fig. 10: PSDF of the response of primary mass $\mathrm{H}_{\mathrm{s}}=$ $12 \mathrm{~m}$; wind speed $90 \mathrm{~km} / \mathrm{hr}$ )
It is seen from Fig. 9 that the force spectrum interacts well with that of the response of the primary structure; interaction of the force is more in the absence of TMD, which implies that there will be a controlled response of the primary structure on attachment of TMD. The controlled response of the primary structure using TMD is shown is Fig 10. It can be seen that the response of the primary system is significantly reduced by the presence of single and multi-tuned mass dampers. A maximum reduction of $23 \%$ in the response is achieved using two TMDs in series. This reduction will increase if the spectrum tends to approach the natural time period of the platform. Table 3 shows the RMS values of the displacements of the primary system for all the configurations considered in the study.

Table 3: RMS of displacement of primary mass for various configurations and load cases

\begin{tabular}{|c|c|c|c|}
\hline \multirow{2}{*}{ Load condition } & \multicolumn{3}{|c|}{ RMS of displacements (m) } \\
\cline { 2 - 4 } & No TMD & Single TMD & $\begin{array}{c}\text { 2 TMD in } \\
\text { series }\end{array}$ \\
\hline $\mathrm{Hs}=6 \mathrm{~m} ; \mathrm{Tp}=10 \mathrm{sec}$ & 0.4 & 0.4 & 0.4 \\
\hline $\mathrm{Hs}=12 \mathrm{~m} ; \mathrm{Tp}=15 \mathrm{sec}$ & 3.44 & 3.55 & 3.59 \\
\hline $\mathrm{Hs}=12 \mathrm{~m} ;$ Wind $\mathrm{speed}=90 \mathrm{~km} / \mathrm{hr}$ & 12.96 & 9.98 & 9.87 \\
\hline
\end{tabular}

\subsection{Mass Distribution Ratio of The Tuned Mass Dampers in Series}

The analysis considered the multi-tuned mass dampers by deploying two TMDs of the same mass, in series. Now, the effect of the mass ratio on the response control is investigated. The mass ratio of the dampers $\left[\mathrm{m}_{1}\left(\mathrm{~m}_{1}+\mathrm{m}_{2}\right)\right]$ are varied and the rmsof the displacement of the TLP are observed. The results for different TMDs mass ratio are given in Table.4. For each case of the mass ratio, $\mathrm{H}_{2}$ optimization technique is used to obtain the optimum values of the parameters of the TMDs.In the table, TMD mass ratio of unity signifies a single TMD and hence those results are not shown in the table.

Table 4 RMS of the displacement for different mass ratio of TMDs

\begin{tabular}{|c|c|c|c|}
\hline \multirow{2}{*}{ Mass ratio } & \multicolumn{3}{|c|}{ RMS displacements $(\mathrm{m})$} \\
\cline { 2 - 4 } & $x_{s}(\mathrm{~m})$ & $x_{1}(\mathrm{~m})$ & $x_{2}$ \\
\hline 0.1 & 3.06 & 8.11 & 9.63 \\
\hline 0.2 & 3.06 & 8.23 & 9.83 \\
\hline 0.3 & 3.06 & 8.33 & 10.06 \\
\hline 0.4 & 3.06 & 8.44 & 10.36 \\
\hline 0.5 & 3.06 & 8.55 & 10.75 \\
\hline 0.6 & 3.05 & 8.67 & 11.32 \\
\hline 0.7 & 3.04 & 8.82 & 12.29 \\
\hline 0.8 & 3.02 & 9.08 & 14.59 \\
\hline 0.9 & 3.1 & 9.46 & 9.68 \\
\hline
\end{tabular}

It can be seen from the table that the response is controlled most effectively for a mass ratio of 0.8 , but the corresponding displacements of the secondary mass is higher. For the mass ratio of 0.1 , the secondary mass displacement is the minimum with only a marginal increase in the response of the platform. Hence for the 
loading cases considered in the analysis and the TMD configurations examined, the mass ratio of 0.1 is seen as the optimum value.

\section{Conclusions}

Dynamic response of a Tension Leg Platform in surge motion is investigated under random sea. Tuned mass dampers, in single and in series are deployed to control the deck motion. Parameters of the multi-tuned mass dampers are optimized for a minimum deck response using $\mathrm{H}_{2}$ optimization. The study examines the effectiveness of TMD on the response control of compliant system like TLP, which is seen as a prime-facie for further motivated research in this domain.Passive control devices like TMDs are not effective when the sea state is not hostile. At normal sea states the primary structure is not excited much in order to absorb its energy. It is also evident that the long natural periods (around 25-30sec) of the floating structures are responsible for the inaction of TMDs in normal sea states. However, in extreme sea stets, it is seen that multi-dampers show effective reduction in the surge response. Based on the numerical studies carried out, it is seen that the response of the primary system becomes more by deploying a single TMD. By deploying multi-dampers, in series, the deck response in surge degree-of-freedom is controlled to its maximum possible value for 0.1 mass ratio.

\section{References}

Alexandros, A. T., Demos, C. A. and Jeffrey, T. S. (2009): Simulation-Based Robust Design of Mass Dampers for Response Mitigation of Tension Leg Platforms, Journal ofEngineering Structures, Vol. 31, pp.847-857. http://dx.doi.org/10.1016/j.engstruct.2008.11.014.

Chandrasekaran, S., Chandak, N. R and Gupta, A. (2006): Stability Analysis of TLP Tethers, Ocean Engineering, Vol. 33, No. 3, pp. 471-482. http://dx.doi.org/10.1016/j.oceaneng.2005.04.015.

Chandrasekaran, S., Bhaskar K., Lino, H. and Brijit, R. (2010a): Dynamic Response Behavior of Multi-Legged Articulated Tower with and without TMD, Proc. International Conf. of Marine Tech. (MARTEC-2010), 11-12 Dec 2010, Dhaka, Bangladesh, pp. 131-136.

Chandrasekaran, S., Bhaskar, K. and Muhammed, H. (2010b): Experimental Study on Dynamic Response Behavior of Multi-Legged Articulated Tower, Proc. $29^{\text {th }}$ International Conf. on Ocean, Offshore and Arctic Engg, OMAE 2010, Shanghai, China, 6-11 ${ }^{\text {th }}$ June, 2010.

Chandrasekaran, S., Gaurav and Jain, A. K. (2010c): Ringing Response of Offshore Compliant Structures, International J. Ocean and climate systems, Multi-Science Publishing, Vol. 1, No 3-4, pp. 133-144. http://dx.doi.org/10.1260/1759-3131.1.3-4.133.

Chandrasekaran, S. Gaurav, Serino, G. and Miranda, S. (2011): Springing and Ringing Response of Triangular TLPs, International Shipbuilding Progress, Vol. 58 (2-3), pp. 141-163. http://dx.doi.org/10.3233/ISP-2011-0073.

Chandrasekaran, S. and Bhattacharyya, S.K. (2012): Analysis and Design of Offshore Structures with Illustrated Examples, Human Resource Development Center for Offshore and Plant Engineering (HOPE Center), Changwon National University Press, Republic of Korea ISBN: 978-89-963915-5-5.

Chandrasekaran , S. and Yuvraj, K. (2013): Dynamic Analysis of a Tension Leg Platform under Extreme Waves, Journal of Naval Architecture and Marine Engineering, Vol. 10, 5968. http://dx.doi.org/10.3329/jname.v10i1.14518.

Fahim, S., Bijan, M. and Andrew, W.T. (2008): A Method of Estimating the Parameters of Tuned Mass Dampers for Seismic Applications, Journal of Engineering Structures, Vol. 30, pp.707-71. http://dx.doi.org/10.1002/(SICI)10969845(199706)26:6<617::AID-EQE664>3.0.CO;2-Z.

Joshi, A. S. and Jangid, R.S. (1997): Optimum Parameters of Multiple Tuned Mass Dampers for Base-Excited Damped Systems,Journal of Sound and Vibration, Vol. 202(5), pp.657-667. http://dx.doi.org/10.1006/jsvi.1996.0859.

Kareem, A. and Kline, S. (1995): Performance of Multiple Tuned Mass Dampers under Random Loading, Journal of Structural Engineering, Vol. 121(2), pp.7595. http://dx.doi.org/10.1061/(ASCE)0733-9445(1995)121:2(348).

Kareem, A.(1983): Mitigation of Wind Induced Motion of Tall Buildings, Journal of Wind Engineering and Industrial Aerodynamics, Vol. 11, pp.273-284. http://dx.doi.org/10.1016/0167-6105(83)90106-X

Lino, H.N. (2012): Dynamic Response Behaviourof Multi-Legged Articulated Tower with Tuned Mass Dampers, M.Sc. Thesis, IIT Madras, pp. 98.

Nam, H. Yozo, F. and Pennung, W. (1997): Optimal Tuned Mass Damper for Seismic Applications and Practical Design Formulas, Journal of Earthquake Engineering and Structural Dynamics, Vol. 26, pp.617-635. http://dx.doi.org/10.1016/j.engstruct.2007.05.007

Toshihiko, A., Osamu, N. and Amr, M.B. (2002): Analytical Solution to $\mathrm{H}_{\infty}$ and $\mathrm{H}_{2}$ Optimization of Dynamic Vibration Absorbers Attached to Damped Linear System, Journal of Vibration and Acoustics, Vol. 124, pp.284-295. http://dx.doi.org/10.1115/1.1456458.

Zuo, L. (2009): Effective and Robust Vibration Control Using Series Multiple Tuned Mass Dampers. Journal of Vibration and Acoustics, Vol. 131, pp.031003-1 -031003-11. http://dx.doi.org/10.1115/1.3085879. 
Zuo, L. and Nayfeh, S. (2005): Optimization of the individual stiffness and damping parameters in multiple tuned mass damper systems, Journal of Vibration and Acoustics, Vol. 127, pp.77-83. http://dx.doi.org/10.1115/1.1855929. 